\section{Cold comfort from Friends}

In a recent letter to the Secretary of State for Energy, Mr Eric Varley, Friends of the Earth (a charitable organisation committed to the conservation, restoration and rational use of the ecosphere) drew attention to the energy savings possible through improved insulation standards and urged that he encourage the introduction of measures which would put an end to unnecessary waste. Here Christine Thomas, a researcher with Friends of the Earth, describes the sort of savings which might be made with a policy for insulation.

Friends of the Earth recently spent a Saturday insulating the roofs of the homes of some 40 old age pensioners throughout the country. They did so in order to draw public attention to the waste caused by heat loss through poorly insulated buildings - an estimated $75 \%$ of the energy consumed for space heating in homes insulated to present standards.

Improved insulation can drastically cut this loss; domestic fuel consumption for heating could be reduced by as much as half while still maintaining the same degree of comfort, or indeed improving it. Such savings matter most for those on small or fixed incomes-in particular the elderly, whose health and incomes can least withstand excessive fuel bills. According to a recent national study about 6 million old people are living in rooms clearly too cold for comfort, between 500,000 and 700,000 of them having unacceptably low body temperatures: clearly candidates for hypothermia.

It was facts like these that prompted the Friends to join with Age Concern (the National Old People's Welfare Council) in a practical gesture to demonstrate the ease with which insulation standards could be improved. Laying glass fibre or mineral wool in an attic costs perhaps $£ 20$, and offers at present prices a fuel cost saving of some $16 \%$ a year in the average semidetached house. Cavity walls can be filled with a variety of foams and mineral substances; solid walls can be faced with insulating board; windows can be double glazed. An average investment of $£ 300$ would cover improvements to the roof, walls and windows, together with draught exclusion, cutting fuel consumption by almost a half. Such a sum can be recouped in less than 10 years by the concomitant savings. Double glazing, however, forms a disproportionately large part of this cost, by comparison with the heat loss it can prevent. Something like a reduction of $35 \%$ in fuel consumption can be achieved by increasing roof and wall insulation alone at a cost of around $£ 100$.

Since domestic heating accounts for $20 \%$ of the total energy consumed in Britain, the potential national saving would be about a tenth of the present amount of energy used, the equivalent of nearly 11 million tonnes of oil each year. Calculations show that the power demand that would be eliminated by such a reduction is some $38,000 \mathrm{MW}$, equivalent to the combined output of some 50 large nuclear reactors. It would, of course, be expensive to insulate existing housing to these standards; a sum of the order of $£ 5,000$ million would be required. This, however, compares favourably, with for instance, the capital cost of the power stations that would otherwise be needed: at least $£ 10,000$ million. Thus there could be a saving of more than $£ 5,000$ million in the long run, not to mention savings in environmental and social costs associated with the installation of large scale generating plant.

It would clearly be far cheaper to insulate all homes fully than to build unnecessary power stations purely to supply heat to waste. Furthermore, by thus relieving some of the pressure on present energy supplies, a very important breathing space would be gained: time to look closely at genuine energy requirements and how they can best be fulfilled, time to develop alternative sources of power, sustainable and safer sources.

The improvement of insulation standards is an area of energy conservation readily amenable to legislative encouragement. Minimum levels for new dwellings are set in the Building Regulations by stipulating the maximum values of $U$ (a measure of the conductivity) permitted. The regulations are at present made under the Public Health Act, which stipulates that they can only be made with specific reference to considerations of health and safety. There is argument as to whether present standards are adequate even for this limited purpose, and proposals for amendments are at present being considered. This, however, seems as far as the present regulations can be pushed.

In order that higher standards, justifiable in terms of energy savings, can be set, the scope of the Building Regulations will have to be widened. This was discussed under the Heath administration when the Department of the Environment was promoting Part III of the Health and Safety at Work etc. Bill, which would have empowered the Secretary of State to make regulations specifically "furthering the conservation of fuel and power" (III, 61, 2, b).

At the discretion of a Local Council, Home Improvement Grants may at present be given for some upgrading of insulation. But the position is not clear; people are unaware of the possibility and many councils are reluctant to give such grants. Making insulation the subject of a Standard Grant would dramatically improve the availability of money; and, together with a positive campaign of public education to ensure that people took advantage of the scheme, would go a long way towards improving standards.

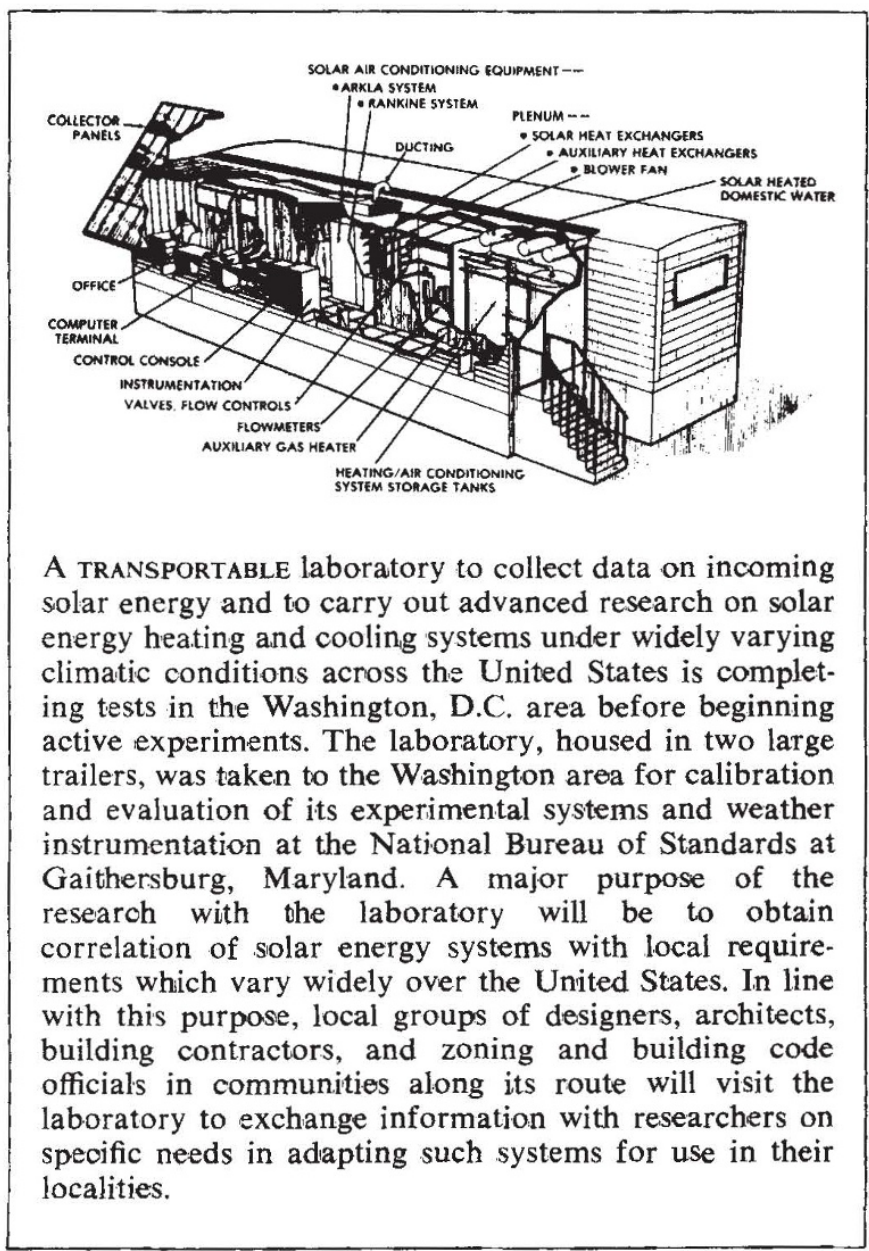

